Research Article

\title{
Study on the Bond Strength of Steel-Concrete Composite Rectangular Fluted Sections
}

\author{
Surya J. Varma $\mathbb{D D}^{1}$ and Jane H. Henderson $\mathbb{i D}^{2}$ \\ ${ }^{1}$ Research Scholar, Department of Civil Engineering, College of Engineering Guindy, Anna University, Chennai, India \\ ${ }^{2}$ Department of Civil Engineering, College of Engineering Guindy, Anna University, Chennai, India \\ Correspondence should be addressed to Surya J. Varma; suryarajesh88@gmail.com
}

Received 3 July 2020; Revised 30 August 2020; Accepted 23 November 2020; Published 15 December 2020

Academic Editor: Behzad Nematollahi

Copyright (C) 2020 Surya J. Varma and Jane H. Henderson. This is an open access article distributed under the Creative Commons Attribution License, which permits unrestricted use, distribution, and reproduction in any medium, provided the original work is properly cited.

\begin{abstract}
Concrete-filled steel tube (CFST) sections are structural members that effectively use the best properties of steel and concrete. Steel tube at the outer perimeter effectively resists tension and bending moments and also increases the stiffness of the section as steel has a high modulus of elasticity. The infilled concrete delays the local buckling of the thin outer steel tube. The interface bond strength plays a major role in the composite action of CFST sections. Provision of rectangular flutes on steel tube on CFST sections will improve the bond failure load and thereby the performance of CFST sections significantly. In this paper, the bond strength and displacement characteristics of steel-concrete composite sections are determined by incorporating rectangular shaped flutes into the steel tube. A total of five sections were tested to assess the influence of flutes on the bond strength. These tested sections are analyzed and are used to develop a finite element model using the finite element software ABAQUS version 6.13. The parameters chosen for the FE study are (i) type of flutes (outward and inward), (ii) $D / t$ ratio (40,60, and 80), (iii) number of flutes $(2,3,4,5$, and 6), and (iv) dimension of flutes $((20 \mathrm{~mm} \times 10 \mathrm{~mm}),(40 \mathrm{~mm} \times 10 \mathrm{~mm})$, and $(60 \mathrm{~mm} \times 10 \mathrm{~mm}))$. Bond failure load is found to be higher for outward fluted sections compared to inward fluted and plain CFST sections.
\end{abstract}

\section{Introduction}

Steel-concrete composite sections are widely used in structural engineering applications due to their excellent composite action under static and dynamic loading conditions. The steel tube effectively resists the bending moment and tension. It acts as longitudinal and transverse reinforcement. These columns resist applied load through the composite action of steel and concrete. High ductility and tensile strength of steel and high compressive strength of concrete effectively complement each other. CFST sections have been widely used in construction due to their high strength, ductility, and excellent static and seismic-resistant properties. Concrete core in CFST sections delays the local buckling of steel tube, whereas steel tube at the outer perimeter confines the concrete infill thereby enhancing the strength and durability. Steel-concrete composite sections have higher strength and stiffness compared to normal reinforced concrete sections. The use of CFST results in smaller sections, as the steel tubes at the outer periphery act as formwork for the concrete and can withstand significant loads before the final setting of the concrete thereby decreasing the construction time. Over the years, several researchers have carried out studies to understand the behavior of steel-concrete composite sections. Wide ranges of steel tubes are being produced nowadays to cater to the growing demand of aesthetically pleasing, architecturally challenging, and cost-effective configurations. One such product is the fluted steel tube. Flutes are the projections provided on the periphery of the steel tube throughout its length. Steel tubes are incorporated with rectangular flutes to enhance the aesthetics and development area by which the moment of inertia of composite member increases. Highstrength requirements for structural engineering application can be satisfied by incorporating rectangular flutes in the steel sheet of CFST sections. The interface bond strength 
between steel and concrete plays a significant role in composite action. So an elaborate study is carried out to assess the interface bond strength and to investigate the influence of various cross-sectional parameters on the bond strength in detail.

Moon et al. [1] carried out an analytical research work to evaluate and improve the design provision for CFST sections with and without internal reinforcement subjected to combined axial load and bending. The strength and behavior of CFST sections with and without internal reinforcement under general combined loading were studied. A finite element model using ABAQUS software was developed to simulate the generalized conditions, including the impact of confinement, slip, and axial load. Parametric studies were conducted by varying the parameters like amount of internal reinforcement, ratio of the tube to the internal reinforcement, axial load ratio, slenderness ratio, and $D / t$ ratio. The finite element results were used to compare the existing P-M interaction curve design models and a proposed model. It was observed that AISC (2010) and Eurocode 4 (CEN 2004) provisions provide P-M interaction curves considering the buckling effects, but the bending resistance of CFTs for low-axial loads is underestimated. Niranjan and Eramma [2] carried out a study for the analysis and design of concrete-filled steel fluted sections. Concrete-filled steel tube (CFST) sections are very useful in structural engineering applications. There is no specific standard codal provision for the analysis and design of CFST sections, but design methods for composite members are incorporated in ACI-318, AISC-LRFD, and EC 4 codal provisions. The authors observed a discrepancy of about 47 percent by adopting EC 4 (Eurocode 4), for a triangular fluted column (TFC). ACI-318 and AISC-LRFD gave about $48 \%$ and $64 \%$, respectively, lesser values compared to the experimental values. Similar results were observed for rectangular fluted sections. The authors compared the results of the three codes with experimental results and found that Eurocode 4 and ACI-318 compare well with each other and are about $55 \%$ and $45 \%$ that of experimental results for triangular fluted columns, whereas AISC-LRFD yields about 35\% lesser values as compared to experimental results. It was concluded that the equations provided in the three codes cannot be used for fluted columns as it is and requires modification. Zhong et al. [3] developed a refined FE model to simulate the actual behavior of CFST sections under axial compression by collecting a wide range of experimental data. A concrete damaged plasticity material model was used to simulate the behavior of CFST sections. For modeling CFST sections, a new concrete strain hardening/softening function was developed. The dilation angle used in the concrete damaged plasticity model was calibrated against test data. Experimental data are compared with the predictions from the new FE model which indicates that the new model developed using ABAQUS software is more versatile and accurate in modeling CFST sections. Chen et al. [4] conducted a push-out test on 18 rectangular steel tubular sections to determine the bond behavior between steel and concrete. The ultimate bond strength is assessed by varying the concrete compressive strength, interface length, crosssectional dimensions, and interface conditions. It is observed that lubricating the interface between steel and concrete always had a significant adverse effect on the interface bond strength. Concrete compressive strength and cross-sectional size have a significant effect on the bond strength of nonlubricated specimens for the range of crosssectional geometries considered which is not mentioned in the European Structural Design Code for composite structures, EN 1994-1-1. A significant reduction in bond strength was observed in steel-concrete composites by interface lubrication, and bond strength reduction of $13 \%$ to $55 \%$ was observed compared to identical specimens with no lubrication. Abendeh et al. [5] summarized the results of push-out tests conducted on concrete-filled steel tubes (CFSTs) incorporating rubberized concrete with the main variables being the recycled rubber replacement ratio at 28 days and one year. The impact of shredded rubber contents on the compressive strength of concrete was investigated by preparing $150 \mathrm{~mm}$ cubes using rubberized concrete mixtures. It was concluded that the use of rubber crumb increased the fresh-state workability and has an adverse influence on the compressive strength of concrete. Comparison of push-out test results of circular and square concrete-filled steel tubes showed that circular sections have a higher bond strength than square sections and an increase in the size of the square section decreases the bond strength. It was observed that incorporation of crumb rubber had only a negligible effect on the ductility of concrete-filled steel columns tested at one year. Ouyang and Kwan [6] developed a finite element method for analyzing the full-range nonlinear behavior of square CFST sections subjected to axial loading. A study on the effect of confinement by using the FE method indicated that, due to the confinement effect, the total axial load capacity of a concrete-filled steel tube at the postpeak stage is significantly higher than the sum of axial load capacities of the steel and concrete sections acting independently without any confinement effect. The FE model has been developed to analyze CFST specimens having normal concrete and normal steel, high-strength concrete and normal steel, and high-strength concrete and high-strength steel. The results indicate that the finite element method is capable of predicting the axial load-strain curve more accurately for different combinations of material strengths.

From the literature review, it can be concluded that several works have been carried out to determine the bond strength of CFST sections by experimental and numerical methods. There is no experimental or analytical work carried out on concrete-filled steel fluted sections to determine the interface bond strength. Only limited work has been carried out to determine the load-carrying capacity of concretefilled steel fluted sections.

In this present work, an attempt has been made to study the influence of $D / t$ ratio, dimension of flute, interface length, and number of flutes on the bond strength, to compare the effectiveness of inward and outward flutes, and finally to develop a validated FE model to accurately predict the bond behavior of steel-concrete composite fluted 
sections. Flutes have been provided in the outer steel shell to increase the moment of inertia of the composite section and thereby increase the bond strength, ultimate load-carrying capacity, ductility, and initial stiffness of CFST sections. Interaction between steel and concrete plays a very significant role in the composite strength. Also, the number, size, and type of flutes will greatly influence the behavior. In this study, the bond strength of concrete-filled steel sections is determined experimentally and compared with analytical results. Outward and inward fluted columns with three and four flutes, respectively, and normal CFST sections were tested. Figure 1 shows the cross-section of the specimens tested. The details of the test specimens are given in Table 1 . The dimension of the rectangular flute was taken as $40 \mathrm{~mm} \times 10 \mathrm{~mm}$ [2]. "SCCFC-4-O" represents steel-concrete composite outward fluted section with 4 flutes. "SCCFC-I-3" represents steel-concrete composite inward fluted section with 3 flutes. Figure 2 shows the test specimens used for the bond study.

\section{Experimental Investigation}

2.1. Material Properties. Ordinary Portland cement of grade 53 with crushed aggregate of size $10 \mathrm{~mm}$ and $12 \mathrm{~mm}$ and manufactured sand (M-sand) were used for preparing the concrete mix of grade M30. Cube tests were carried out to determine the compressive strength of concrete at 7 days and 28 days, and an average cube compressive strength value is taken for analytical investigation. Table 2 shows the details of the mix proportion.

Three tension coupons were tested as per ASTM A-370 standards to assess the properties of the steel tube [7]. The stress-strain behavior of the steel obtained from these tests is given in Figure 3. These values of the stress-strain curve were used for the analytical investigation.

2.2. Preparation of Test Specimen. MIG-welded steel tubes were used for the preparation of specimens. The inner surface of the steel tube was cleaned of any rust, loose scale, and any deposit of grease or oil. Two $v$-notches were provided at the bottom for the expulsion of air from the specimen during the push-out test. Concrete was filled in the steel tube up to $450 \mathrm{~mm}$ length. $50 \mathrm{~mm}$ gap was provided at the bottom for the concrete to slip during axial loading.

2.3. Test Setup. The specimens were tested in a $1000 \mathrm{kN}$ capacity Universal Testing Machine. The columns were kept in a vertical position with a $50 \mathrm{~mm}$ air gap at the bottom end.

A solid block having a cross-sectional area less than the specimen was placed on the concrete core. This ensures that the axial load was applied only to the concrete core inside the steel tube and allows the concrete core to slip through the outer steel tube. The load was applied at the rate of $4 \mathrm{kN} / \mathrm{min}$, and axial shortening was recorded at regular intervals using a deflectometer having a least count of $0.01 \mathrm{~mm}$. Bond strength is calculated based on the load at slip and area of contact. Fluted sections exhibit a stiff load versus slip behavior. Initially, slip at the steel-concrete interface occurred gradually, and thereafter, sudden downward movement was observed and large displacement was recorded. The experimental setup is shown in Figure 4.

2.4. Interface Bond Strength. Average bond stress is adopted to represent interface bond strength between steel and concrete. Average bond strength $\left(\tau_{\mathrm{u}}\right)$ is calculated based on the bond failure load of concrete-filled steel fluted sections [5]:

$$
\tau_{u}=\frac{\mathbf{P}}{\mathbf{A}},
$$

where $\mathbf{P}$ is the bond failure load and $A$ is the interfacial area between the internal surface of steel and outer surface of the concrete.

For steel-concrete composite fluted sections used for the experiment, bond strength is calculated as follows:

$$
\tau_{u}=\frac{\mathbf{N}_{\mathbf{u}}}{\left[\pi \mathbf{D}+2 \mathbf{d}_{\mathbf{f}} \mathbf{n}\right] \mathbf{L}},
$$

where $N_{\mathrm{u}}$ is the bond failure load which is calculated as the load at which concrete starts slipping obtained from the load-slip curve, $A$ is the interfacial area, $D$ is the diameter of the specimen, $n_{\mathrm{f}}$ is the number of flutes, $d_{\mathrm{f}}$ is the depth of flute, and $L$ is the interface length.

The test results are shown in Table 3. It can be seen that the bond strength is higher for concrete-filled steel fluted crosssections with outward flutes and least for cross-sections with inward flutes irrespective of the number of flutes. Provision of inward flutes has a negative effect since local failure occurs near the sharp edges in the inward fluted sections. This is due to stress concentration near the sharp edges in the inward fluted cross-sections. Concrete-filled steel fluted cross-sections with 4 inward flutes have the least bond strength. When the number of inward flutes increases, bond strength decreases due to the decrease in the development area and an increase in stress concentration at the sharp corners, resulting in a decrease in bond failure load. The bond strength of 4outward fluted cross-section is $2.22 \%$ higher than 3-outward fluted cross-section and $8.66 \%$ higher than normal CFST section. The bond strength of 4 inward fluted cross-section is $15.29 \%$ lower than 3 inward fluted cross-section and $43.30 \%$ lower than normal CFST section. When the bond strength increases, the composite action of steel and concrete becomes significant, and load-carrying capacity of the columns increases. It can be concluded that outward fluted cross-sections perform better than inward fluted cross-sections. Interaction between steel and concrete is higher when outward flutes are incorporated in normal CFST sections. The performance of steel-concrete composite sections can be improved by incorporating rectangular outward flutes satisfying the growing demand of highly resistant composite structures in structural engineering applications. Interface bond strength is generally developed from the chemical adhesion, microlocking, and macrolocking occurring between the concrete core and steel surface [5]. There is no slip between steel and concrete core in the initial stage of loading due to chemical adhesion. The mechanisms of resistance in CFST are attributable to adhesion 


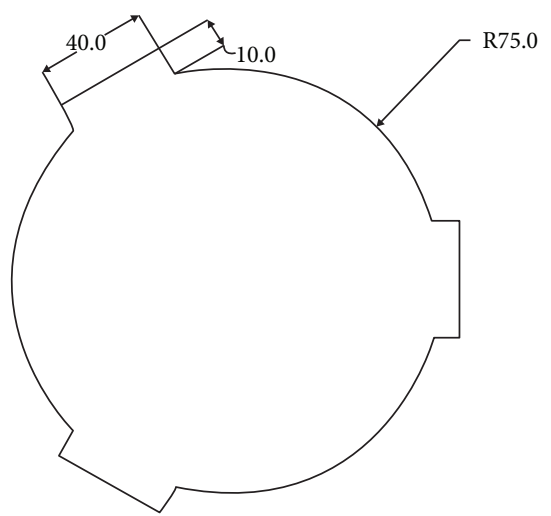

(a)

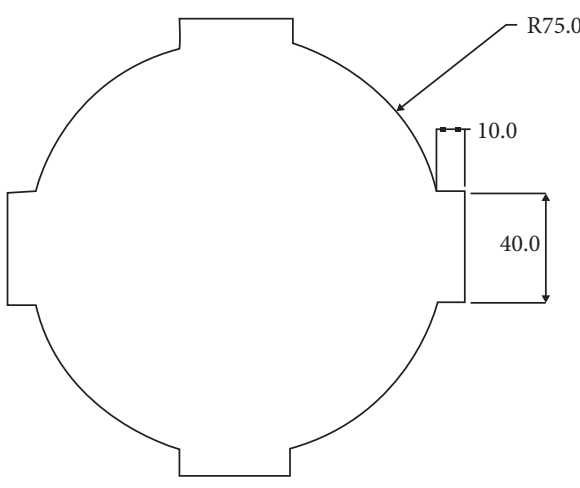

(c)

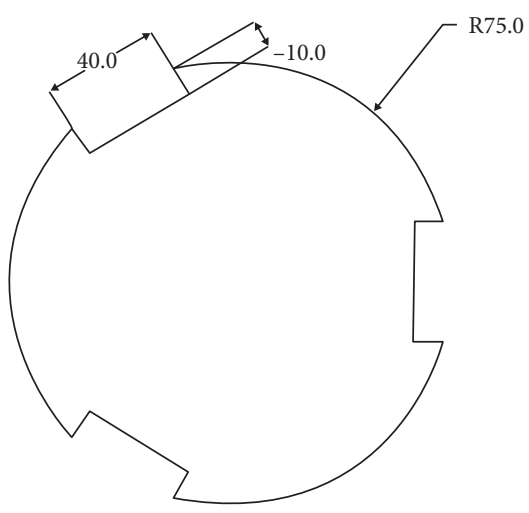

(b)

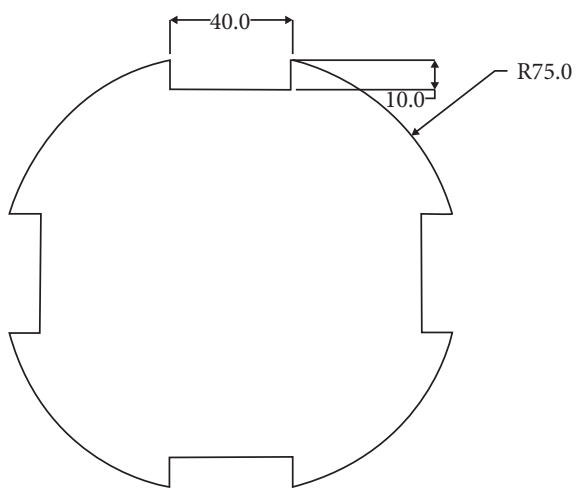

(d)

Figure 1: Cross-section details: (a) 3-outward fluted section; (b) 3-inward fluted section; (c) 4-outward fluted section; (d) 4-inward fluted section.

TABLE 1: Details of the specimen.

\begin{tabular}{|c|c|c|c|c|c|c|c|}
\hline Sl no. & Nomenclature & No. of flutes & Position of flutes & Length $(\mathrm{mm})$ & Diameter $(\mathrm{mm})$ & Thickness of steel tube & Flute dimension \\
\hline 1 & SCCFC-4-O & & Outward & & & \multirow{5}{*}{$3 \mathrm{~mm}$} & \multirow{4}{*}{$40 \mathrm{~mm} \times 10 \mathrm{~mm}$} \\
\hline 2 & SCCFC-4-I & 4 & Inward & & & & \\
\hline 3 & SCCFC-3-O & 3 & Outward & 500 & 150 & & \\
\hline 4 & SCCFC-3-I & 3 & Inward & & & & \\
\hline 5 & CFST & NA & & & & & NA \\
\hline
\end{tabular}

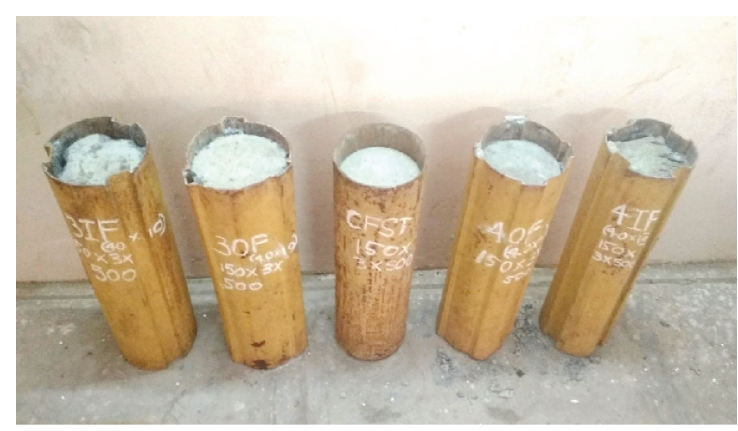

Figure 2: Test specimens.

that is developed by chemical adherence between concrete and steel, and it is a fragile mechanism which is significant only in the early stages of loading. This phenomenon is present only in case in which there is contact between the surfaces of steel and concrete and depends on the proportion of water and cement and is related to shrinkage of concrete. Friction force becomes active when adhesion forces fail and depends primarily on the roughness of the interface surface between steel and concrete. This mechanism is microlocking. Wedge effect begins when all the concrete core inside the steel tube is in motion, i.e., when the microbonds and local friction fail. A large-scale frictional mechanism is hence generated due to dimensional irregularities of the steel tube that restricts concrete displacements. This mechanism is called macrolocking [4].

It was observed during the experiment that a linear relationship was observed between the load and axial deformation irrespective of the geometry of flutes and number of flutes at the elastic stage. When the load approached the ultimate failure load, the crushing of confined concrete was heard, and then, the load decreased significantly leading to 
TABLE 2: Mix proportion details.

\begin{tabular}{|c|c|c|c|c|c|c|c|}
\hline \multirow[t]{2}{*}{ Grade of concrete } & \multirow[t]{2}{*}{$\mathrm{W} / c$} & \multirow[t]{2}{*}{ Portland cement $\left(\mathrm{kg} / \mathrm{m}^{3}\right)$} & \multirow[t]{2}{*}{ M-sand $\left(\mathrm{kg} / \mathrm{m}^{3}\right)$} & \multicolumn{2}{|c|}{ Aggregate $\left(\mathrm{kg} / \mathrm{m}^{3}\right)$} & \multicolumn{2}{|c|}{$\begin{array}{l}\text { Average cube } \\
\text { compressive } \\
\text { strength, } f_{\mathrm{ck}} \\
\left(\mathrm{N} / \mathrm{mm}^{2}\right)\end{array}$} \\
\hline & & & & $12 \mathrm{~mm}$ & $10 \mathrm{~mm}$ & 7 days & 28 days \\
\hline M30 & 0.50 & 390 & 672 & 585 & 585 & 28.9 & 39.69 \\
\hline
\end{tabular}

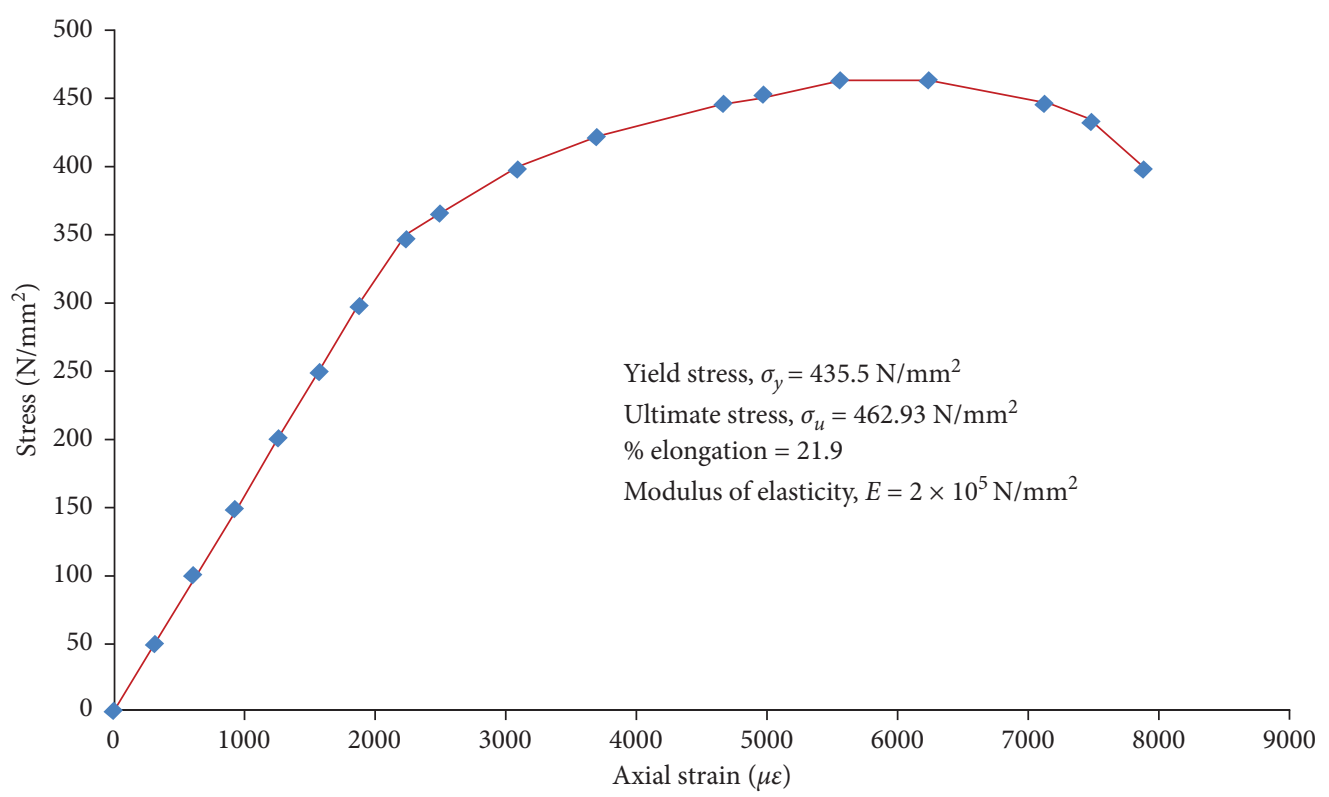

FIgURE 3: Stress-strain curve for steel.

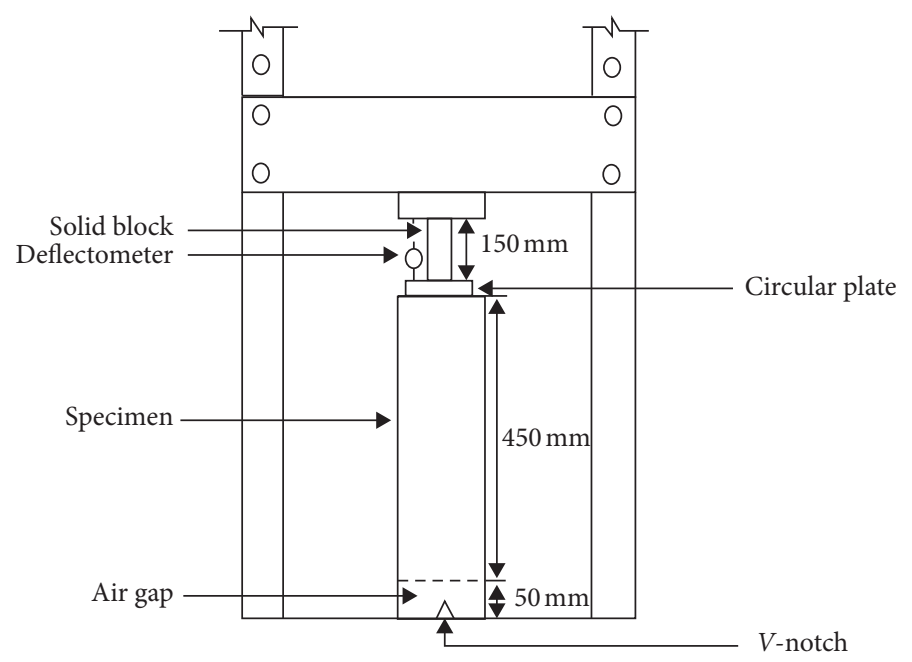

FIgURE 4: Experimental setup.

TABLE 3: Bond strength of the specimens tested.

\begin{tabular}{lcc}
\hline Sl no. & Nomenclature & Bond strength $\left(\mathrm{N} / \mathrm{mm}^{2}\right)$ \\
\hline 1 & SCCFC-4-O & 1.38 \\
2 & SCCFC-4-I & 0.72 \\
3 & SCCFC-3-O & 1.35 \\
4 & SCCFC-3-I & 0.85 \\
5 & CFST & 1.27 \\
\hline
\end{tabular}

loss of bond between steel and concrete and the steel tube started yielding.

\section{Analytical Investigation}

The experimental results were compared using the FE model developed using ABAQUS. After several trials, the angle of 
friction was taken as $50^{\circ}$, flow stress ratio as 1 , and dilation angle was taken as $30^{\circ}$ [8] to simulate the actual behavior. The coefficient of friction between steel and concrete is taken as 0.6 [3]. 8-noded brick elements (C3D8) with 24 DOFs are used for the modeling of concrete core, and 4-noded shell element (S4R) [9] with 6 DOF is used for modeling of steel. Poisson's ratio for concrete is taken as 0.2 and that of steel is taken as 0.3 [8]. Displacement degrees of freedom in all three directions (U1, $\mathrm{U} 2$, and $\mathrm{U} 3$ ) and rotational degrees of freedom in all three directions are restrained to be zero at bottom. "Encastre" condition is used to give a fixed condition at bottom. Encastre condition constraints all displacements and rotations at a node. Nodes at the top end are kept free in the U3 direction and restrained to be zero in all other directions. The interface between concrete and steel was modeled using contact pair option. Modeling of interfaces requires defining two surfaces, namely, master surface and slave surface. The inner surface of steel is taken as the master surface, and the outer surface of concrete is taken as the slave surface for incorporating interaction between steel and concrete.

Eigen values obtained in linear perturbation buckling analysis are used to get the bond failure load of the specimen using the Static Riks method. An eigenvalue buckling analysis can be used to determine the critical load of stiff structures. The unstable geometrically nonlinear collapse of a structure is predicted using the Static Riks method. An eigenvalue buckling analysis is done by using the Static Riks method to provide complete details of the collapse of the structure. Concrete damage is modeled using Drucker-Prager plasticity model which is used to describe the inelastic behavior of concrete. Interaction between steel and concrete is provided using the penalty option in tangential behavior which uses a stiffness method that allows some relative motion of the surface (elastic slip) when they are bonded. The dimension of the flute is taken as $40 \mathrm{~mm} \times 10 \mathrm{~mm}$, and the radius of the circular section as $75 \mathrm{~mm}$ [2].

Figure 5 shows the meshed model of a typical outward and inward rectangular fluted column. Figure 6 shows the deformed shapes of the FE model. The comparison between load vs slip behavior of the tested sections with the FE model is shown in Figure 7. It can be seen that the FE model is capable of simulating the experimental behavior closely within a margin of $4 \%$. Provision of flutes either outward or inward increases the initial stiffness of the section compared to CFST sections.

From Figure 7 , it is observed that the ascending rigid branch is characterized by very small displacements at the interface between steel and concrete, and it is related to the mechanism of adhesion. Once the adhesion reaches its peak value, the chemical bond between steel and concrete is broken; concrete core starts to move inside the steel tube. At this stage, the phenomenon of friction between steel and concrete due to surface roughness begins. When a local rupture mechanism occurs leading to the crushing of concrete at the interface, a new frictional mechanism related to macroimperfections of the steel tube begins. This contribution of friction continues until the complete expulsion of the confined concrete occurs due to applied load.

\subsection{Empirical Equation for Determining Bond Strength.} An empirical equation is suggested to determine the bond strength of SCCF sections based on the numerical study:

$$
\tau_{\mathbf{u}}=\frac{\mathbf{N}_{u} \tan \boldsymbol{\theta}}{\left[\pi \mathbf{D}+2 \mathbf{d}_{f} \mathbf{n}_{f}\right] \mathbf{L}},
$$

where $N_{\mathrm{u}}$ is the bond failure load, $\theta$ is the angle of friction, $D$ is the diameter of the specimen, $n_{\mathrm{f}}$ is the number of flutes, $d_{\mathrm{f}}$ is the depth of flute, and $L$ is the interface length.

Bond failure load $\left(N_{\mathrm{u}}\right)$ is calculated as the load at which concrete starts slipping through the steel tube in the pushout test. From the numerical study, the angle of friction of $50^{\circ}$ is found to give accurate results in the validation of experimental results using ABAQUS. The angle of friction between $45^{\circ}$ to $50^{\circ}$ is found to give accurate values of bond strength for SCCF sections with normal grade concrete infill.

Dilation angle $(\Psi)$ is an important parameter to determine the plastic flow potential [1]. The following equation is used to determine the dilation angle for steel-concrete composite fluted cross-sections based on numerical analysis using ABAQUS:

$$
\begin{aligned}
& \psi=16\left(1+\xi_{c}\right) \text { for } \xi_{c} \leq 1, \\
& \psi=13.5\left(1+\xi_{c}\right) \text { for } \xi_{c}>1,
\end{aligned}
$$

where $\xi_{c}$ is the confinement index calculated using the following formula [10]:

$$
\xi_{c}=\frac{\mathbf{f}_{y} \mathbf{A}_{s}}{\mathbf{f}_{c k} \mathbf{A}_{c}},
$$

where $A_{s}$ is the area of steel and $A_{c}$ is the area of concrete.

3.2. Parametric Study Using ABAQUS. Based on these preliminary results, further elaborate studies to understand the effect of flutes on CFST sections were confined to outward fluted cross-sections. Nomenclature adopted for the FE models is as follows: for example, SCCFC-40-2a represents steel-concrete composite fluted cross-section having 2 number of flutes with $D / t$ ratio 40 and " $a$ " denotes flute dimension of $20 \mathrm{~mm} \times 10 \mathrm{~mm}$.

SCCFC-60-4b denotes the SCCF section having 4 number of flutes with $D / t$ ratio 60 , and " $b$ " represents flute dimension of $40 \mathrm{~mm} \times 10 \mathrm{~mm}$. SCCFC-80-6c represents the SCCF section having 6 number of flutes with $D / t$ ratio 80 , and " $c$ " represents flute dimension of $60 \mathrm{~mm} \times 10 \mathrm{~mm}$. The diameter of the specimens was fixed as $150 \mathrm{~mm}$. The load versus slip behavior of all the sections analyzed is shown in Figure 8.

There is no substantial decrease in the bond failure load for SCCF cross-sections with an increase in $D / t$ ratio from 40 to 60 . Increase in the number of flutes increases the bond failure load for cross-sections with $D / t$ ratio 40 to 60 , whereas for cross-sections with $D / t$ ratio 80 , the number of flutes does not significantly influence the bond failure load. For cross-sections with a lower $D / t$ ratio, increase in the 


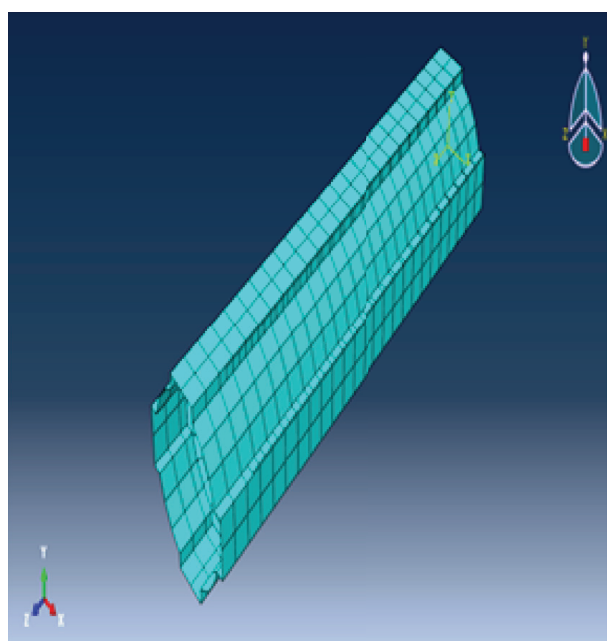

(a)

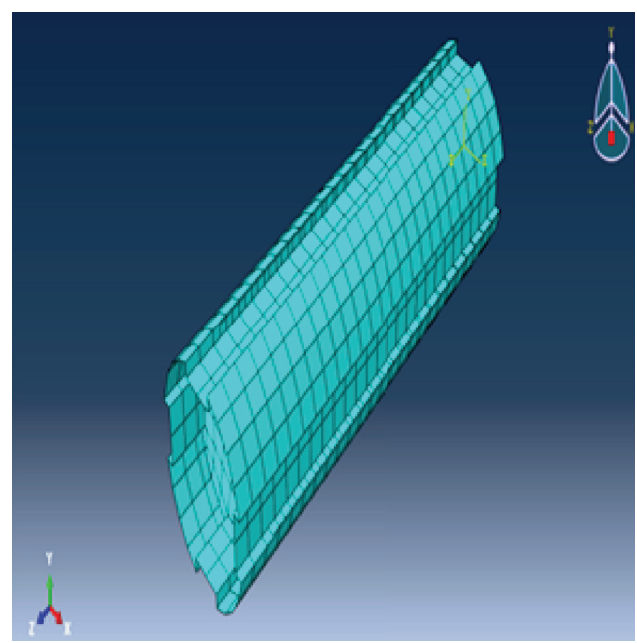

(b)

FIgURE 5: Meshed model: (a) outward fluted section; (b) inward fluted section.

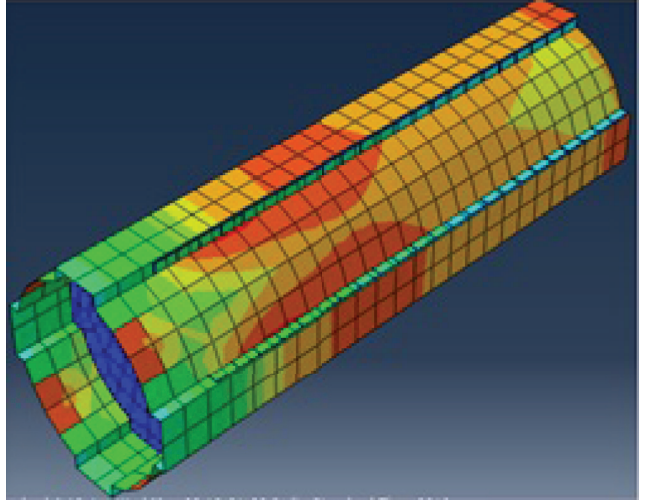

(a)

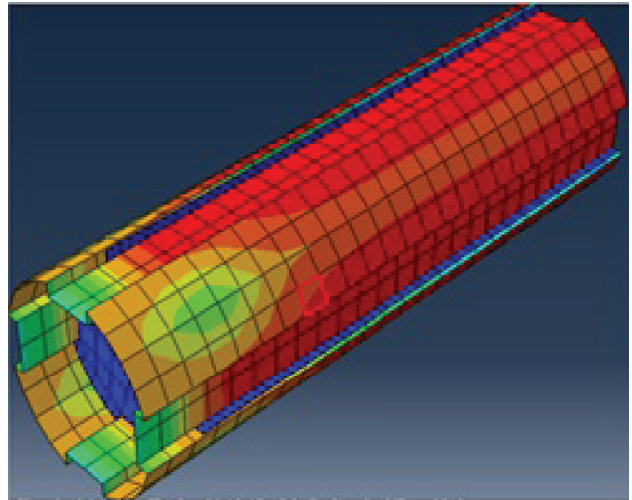

(b)

Figure 6: Deformed shapes: (a) outward fluted section; (b) inward fluted section.

number of flutes increases the bond failure load by about $15-29 \%$, whereas columns with $D / t$ ratio 60 , increase in the number of flutes, resulting in about $11-12 \%$ increase in bond failure load irrespective of the size of the flute. For crosssections with $D / t$ ratio 80 , with an increase in the size of flute, there is $6-13 \%$ increase in the bond failure load. Figure 9 shows the variation in bond failure load with the number of flutes for various flute sizes.

Bond failure load increases with an increase in the number of flutes irrespective of the flute size. For SCCF cross-sections with $D / t$ ratio 40 , flute dimension $40 \mathrm{~mm} \times 10 \mathrm{~mm}$, and for SCCF cross-sections with $D / t$ ratios 60 and 80 , flute dimension $60 \mathrm{~mm} \times 10 \mathrm{~mm}$ are found to give best results. From Figure 10, it can be seen that an increase in the contact area by $22-44 \%$ increases the bond failure load by $14-45 \%$ irrespective of the number of flutes.

\subsection{Effect of Number of Flutes on Bond Strength.} Figure 11 shows the variation in bond strength with the number of flutes for different $D / t$ ratios of sections. It can be seen that the bond strength decreases with an increase in the number of flutes for cross-sections with a larger $D / t$ ratio of 60 and 80 irrespective of flute dimension.

3.4. Effect of D/t Ratio on Bond Strength. Figure 12 shows the variation in bond strength with the dimension of the flute for $D / t$ ratios 40,60 , and 80 , respectively. It is observed that bond strength is highest for SCCFC with flute dimension $40 \mathrm{~mm} \times 10 \mathrm{~mm}$ irrespective of the $D / t$ ratio. It is also found that the bond strength decreases with an increase in the $D / t$ ratio. So, it can be concluded that increase in the $D / t$ ratio of rectangular fluted cross-sections will not enhance the bond strength of composite cross-sections irrespective of the flute dimension.

3.5. Effect of Interface Area on Bond Strength. Figure 13 shows the variation in bond strength with the interface area for $D / t$ ratios 40,60 , and 80 , respectively. The distribution of bond strength is not uniform and is found to decrease with an increase in the interface area. 


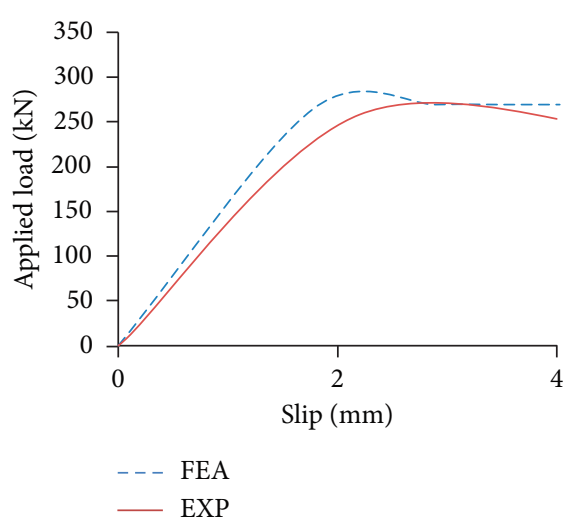

(a)

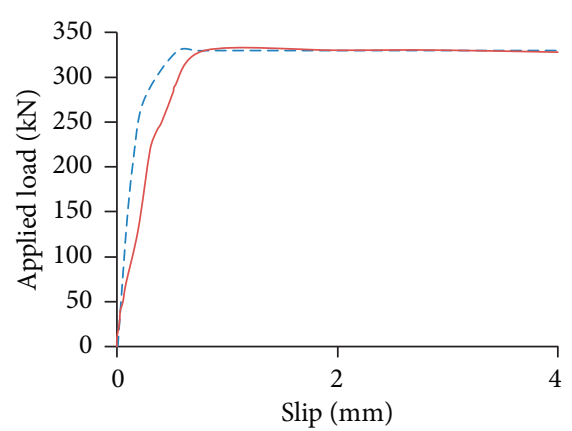

--- FEA

EXP

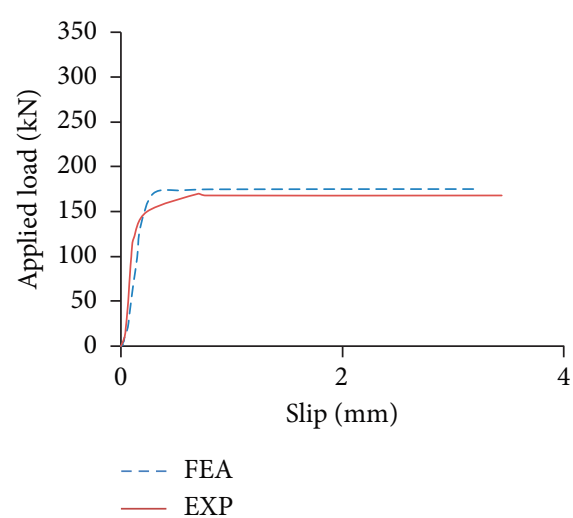

(c)

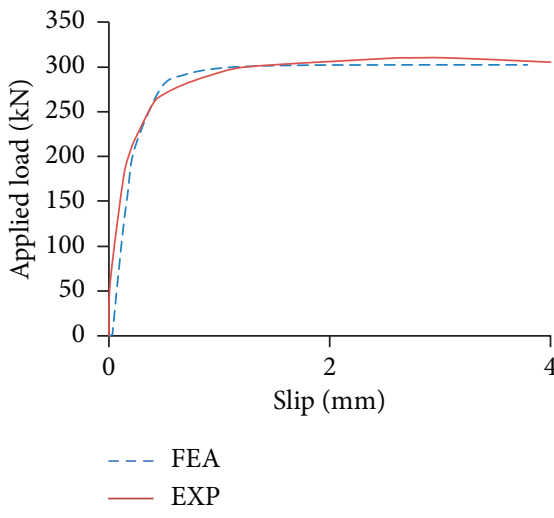

(d) (b)

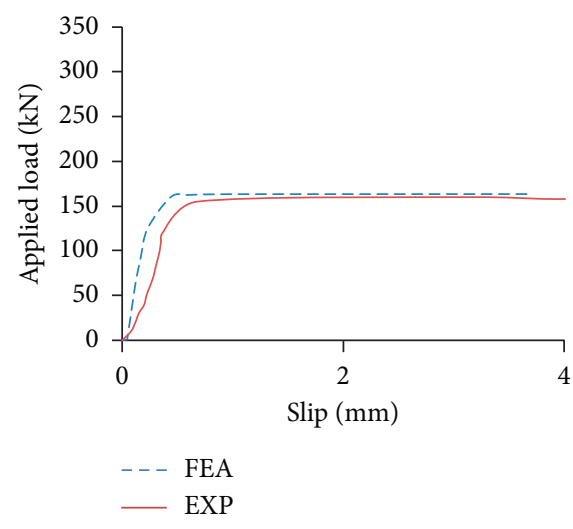

(e)

Figure 7: Applied load vs slip behavior: (a) CFST; (b) SCCFC-4-O; (c) SCCFC-4-I; (d) SCCFC-3-O; (e) SCCFC-3-I.

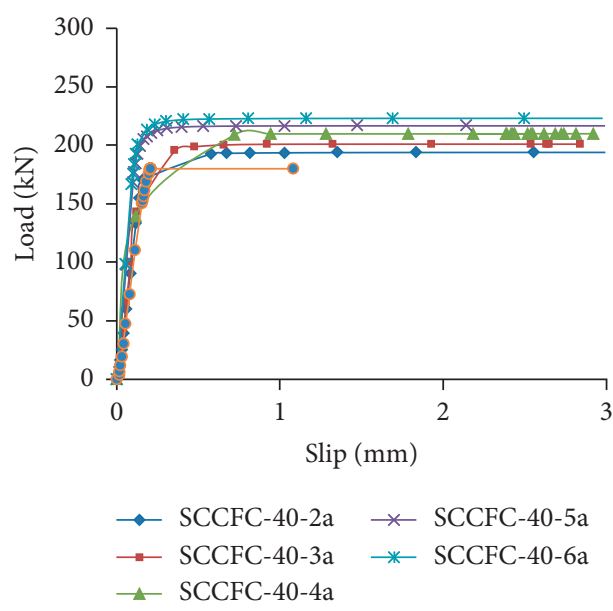

(a)

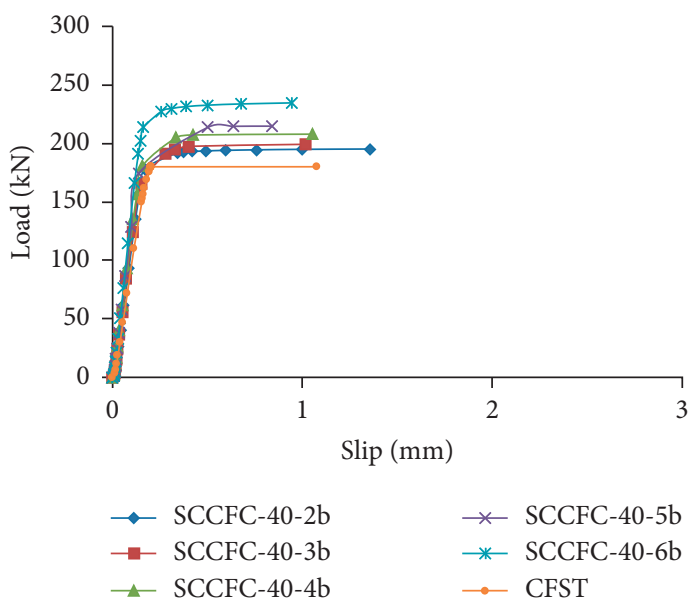

(b)

Figure 8: Continued. 


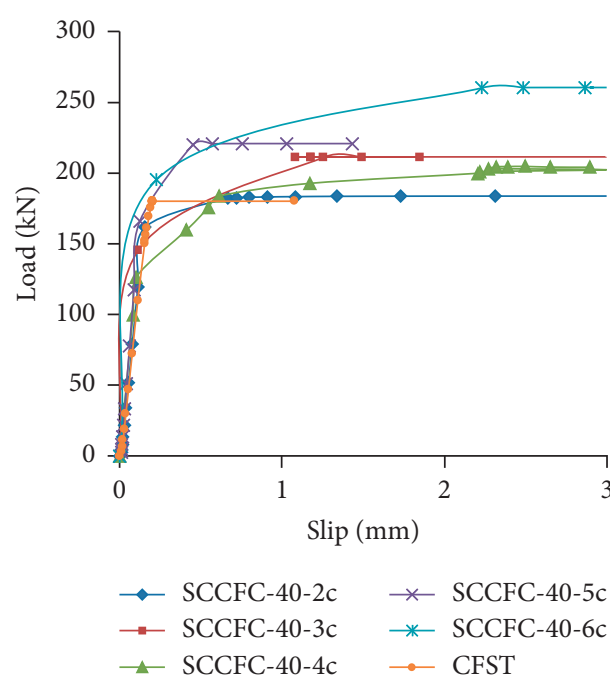

(c)

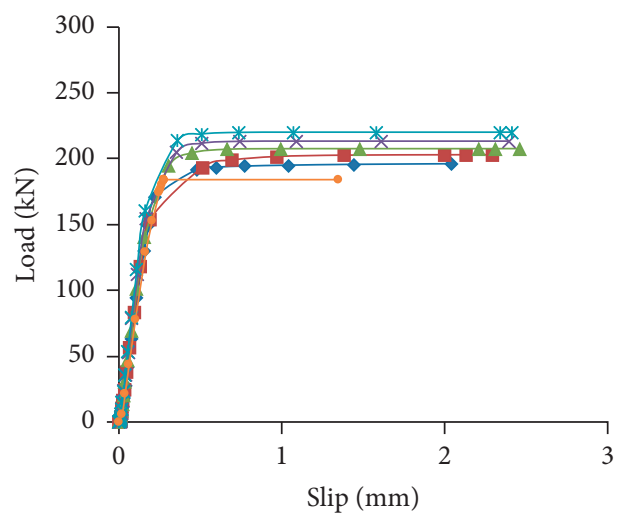

$\rightarrow$ SCCFC-60-2b $\rightarrow$ SCCFC-60-5b

$\rightarrow$ SCCFC-60-3b $\rightarrow$ SCCFC-60-6b

$\leadsto$ SCCFC-60-4b $\rightarrow$ CFST

(e)

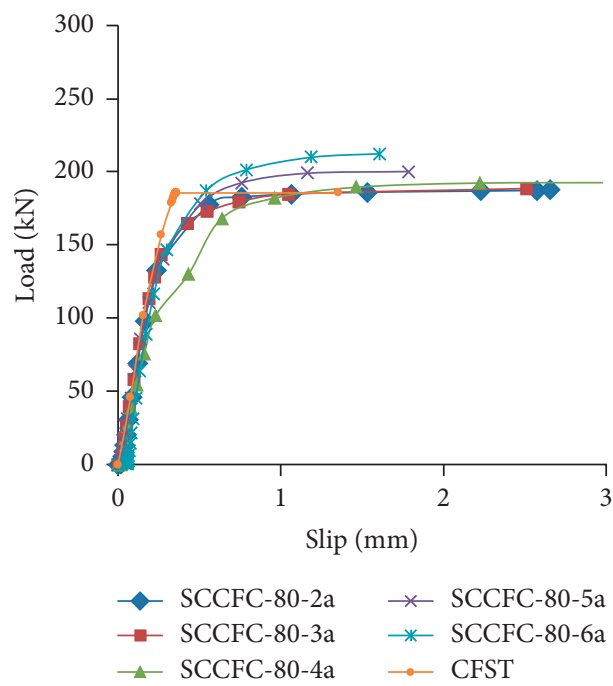

(g)

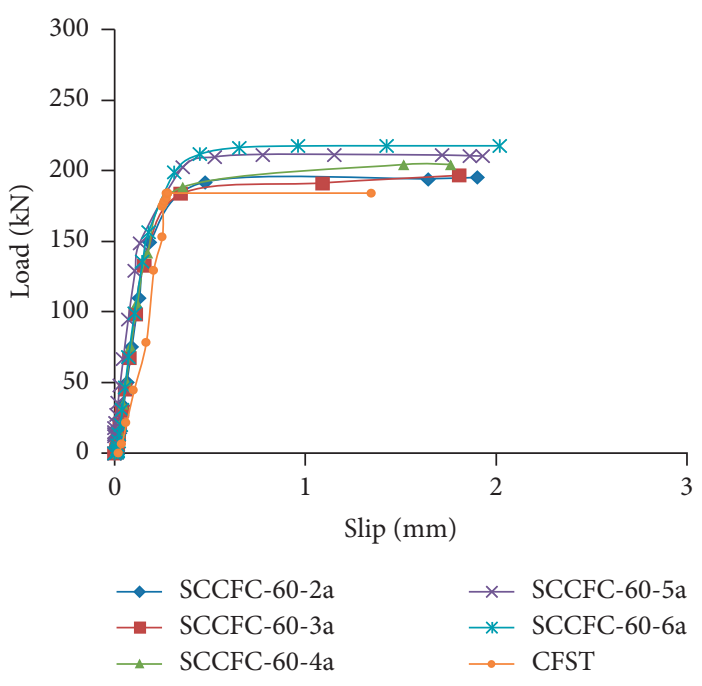

(d)

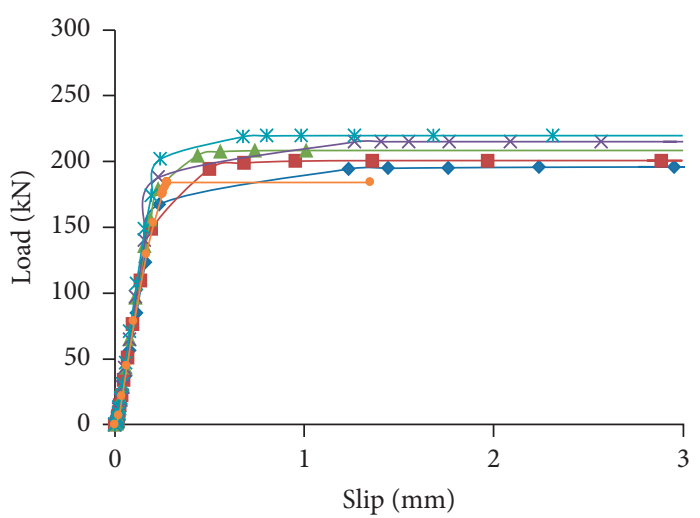

$\rightarrow$ SCCFC-60-2c $\rightarrow$ SCCFC-60-5c

$\rightarrow$ SCCFC-60-3c $\rightarrow$ SCCFC-60-6c

$\multimap$ SCCFC-60-4c $\rightarrow$ CFST

(f)

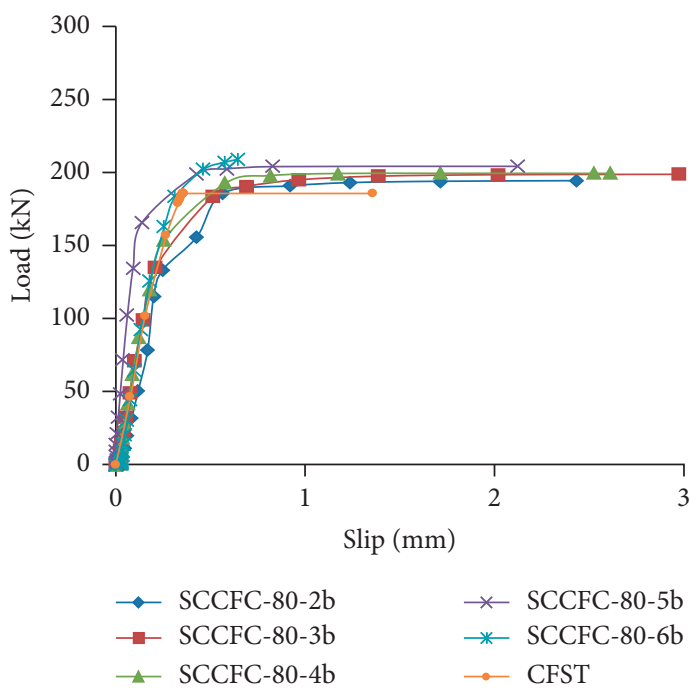

(h)

FIgURE 8: Continued. 


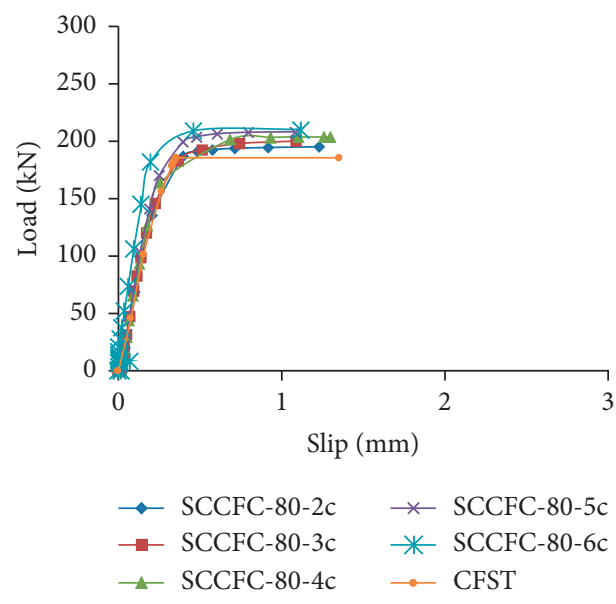

(i)

FIGURE 8: Load vs slip behavior.

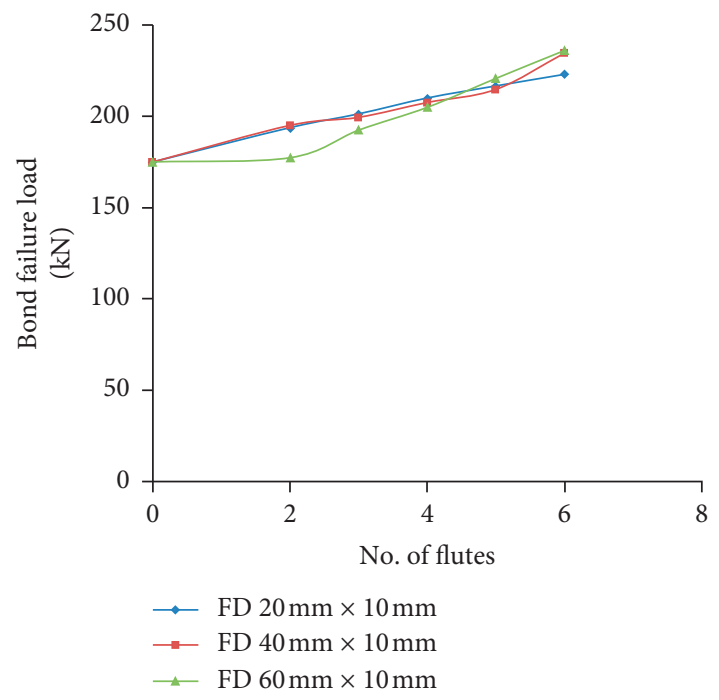

(a)

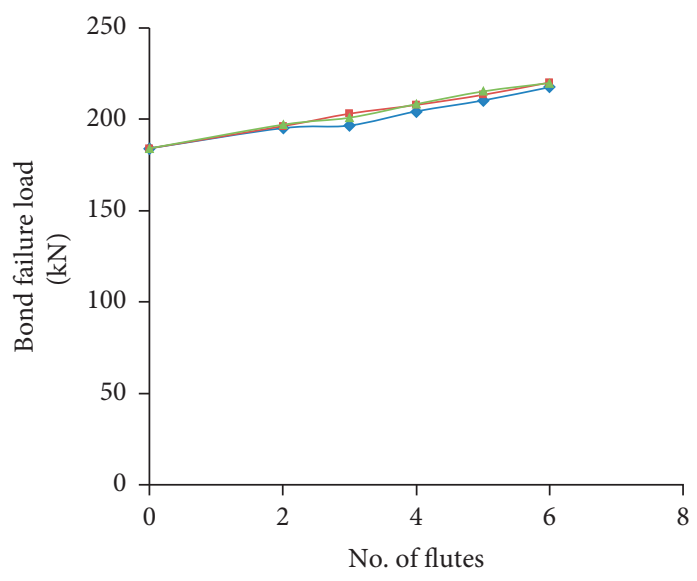

- FD $20 \mathrm{~mm} \times 10 \mathrm{~mm}$

$\rightarrow$ FD $40 \mathrm{~mm} \times 10 \mathrm{~mm}$

$\leadsto$ FD $60 \mathrm{~mm} \times 10 \mathrm{~mm}$

(b)

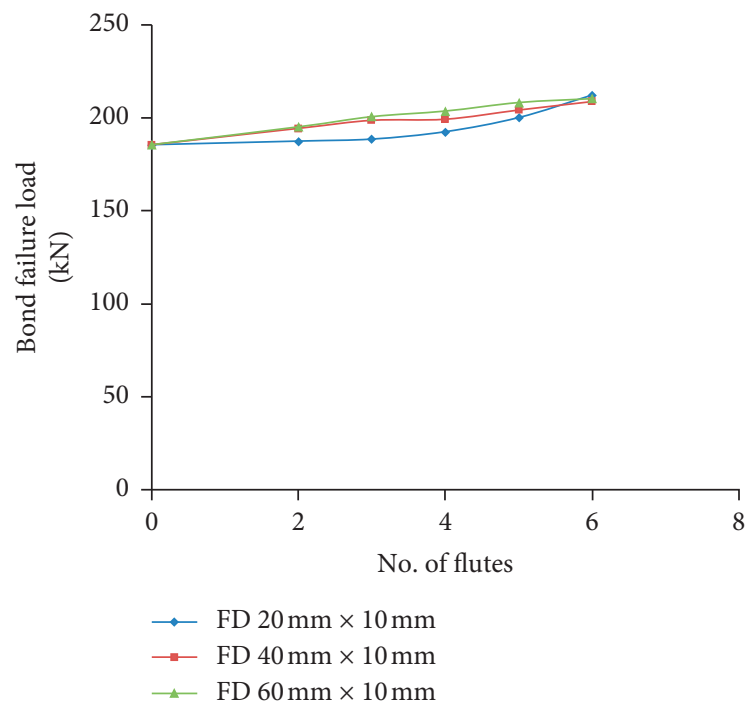

(c)

Figure 9: Bond failure load vs number of flutes: (a) $D / t=40$; (b) $D / t=60$; (c) $D / t=80$. 


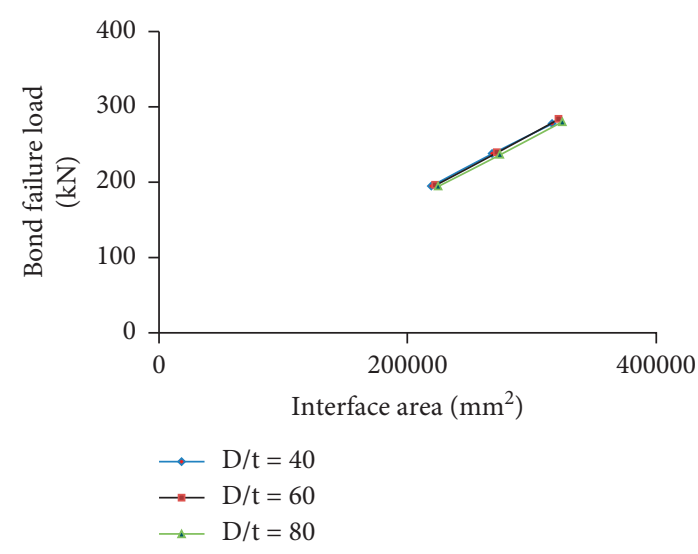

(a)

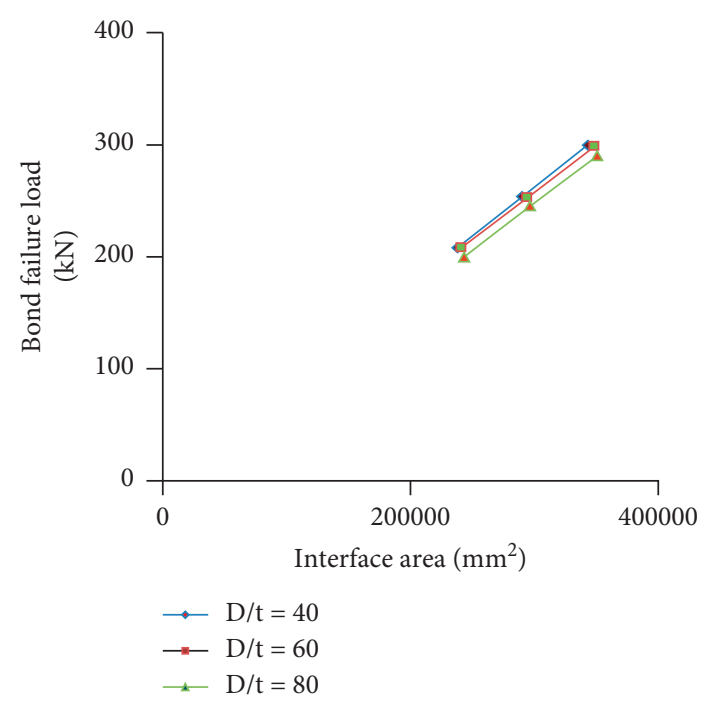

(c)

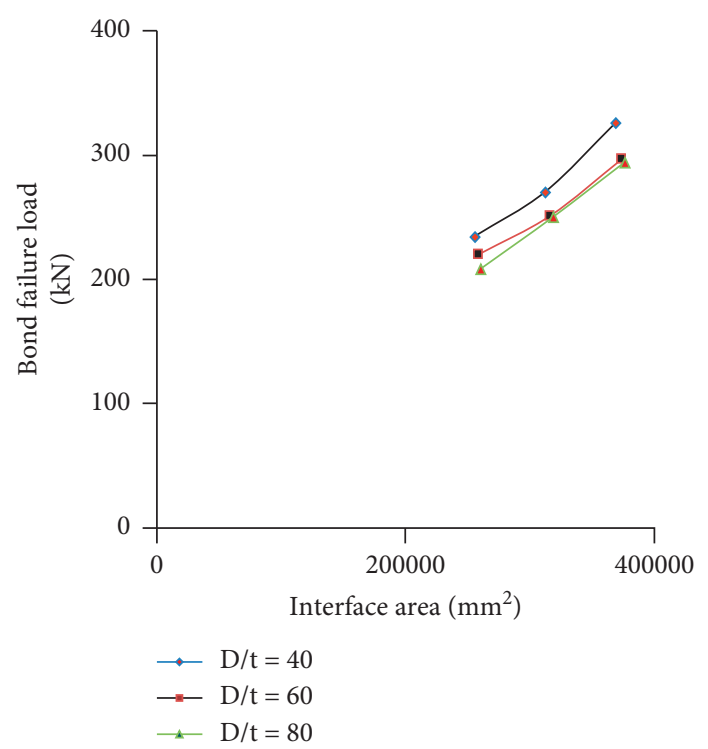

(e)

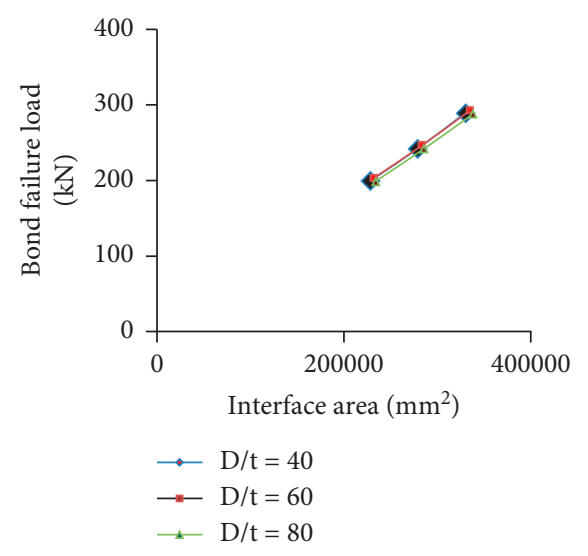

(b)

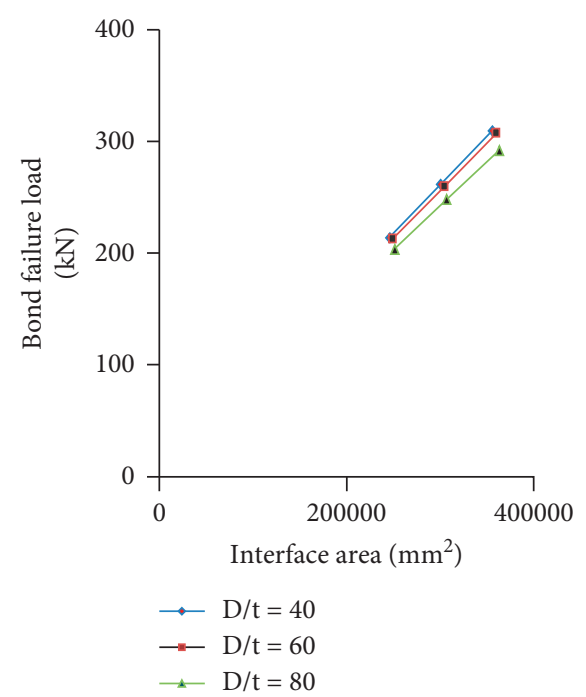

(d) 


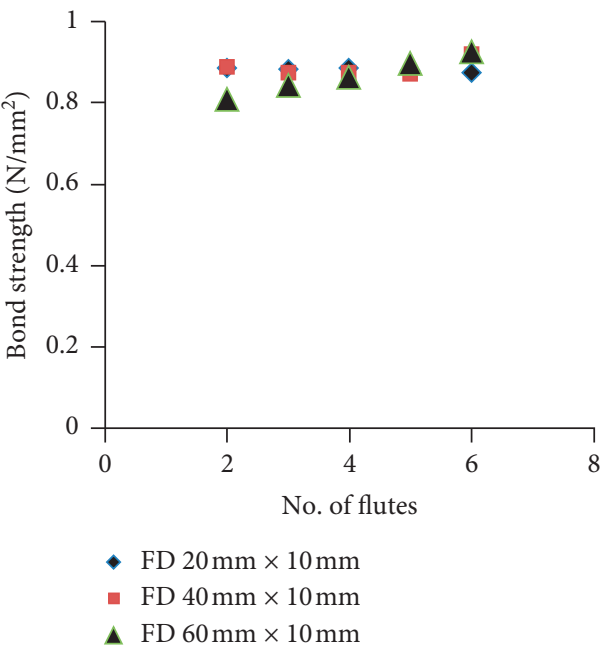

(a)

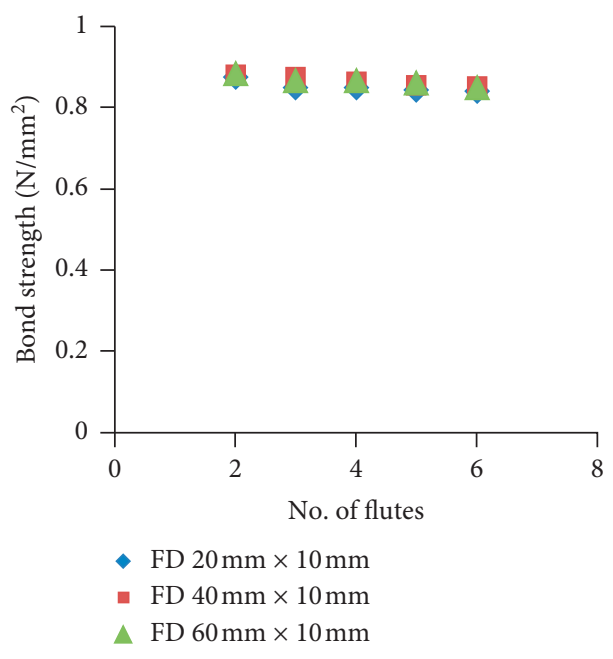

(b)

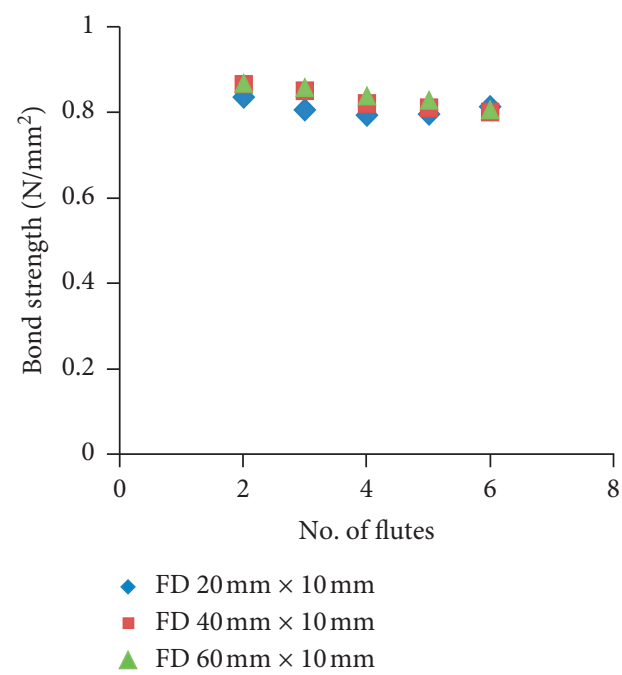

(c)

Figure 11: Variation in bond strength with number of flutes: (a) $D / t=40$; (b) $D / t=60$; (c) $D / t=80$.

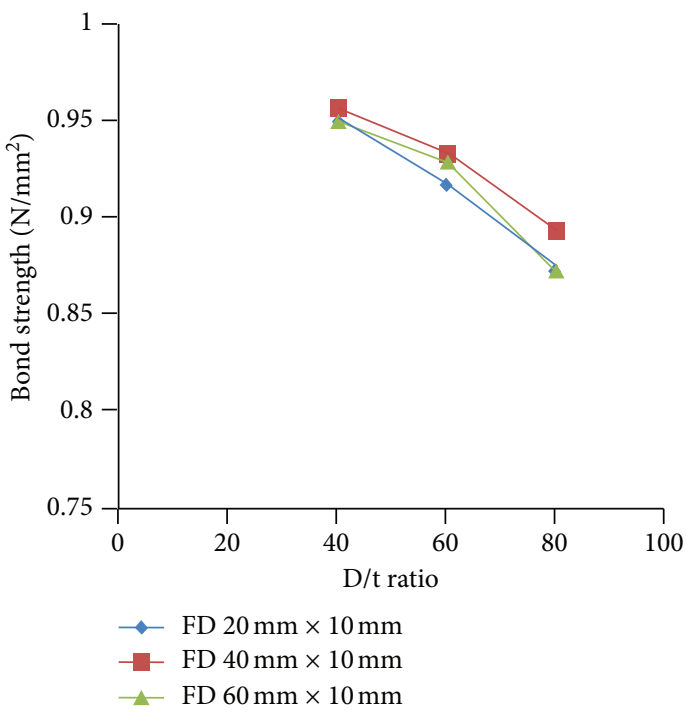

FIGURE 12: Variation in bond strength with $D / t$ ratio.
Table 4 shows the comparison of bond strength obtained in experimental investigation with proposed formula. The available codal provisions for the composite section design do not take into account the influence of the angle of friction on bond strength of normal CFST cross-sections. The suggested equation to determine the bond strength of SCCF cross-sections considers the influence of the angle of friction on bond strength, and it can be effectively used for normal CFST sections also. Table 5 shows the comparison of bond strength of numerical models with proposed formula.

From Table 5, it was observed that the bond strengths of SCCF cross-sections with $D / t$ ratio 40 are higher than that of normal CFST cross-sections except for SCCF cross-sections with flute dimension $60 \mathrm{~mm} \times 10 \mathrm{~mm}$ having number of flutes 2,3 , and 4 , respectively. But bond strengths of SCCF crosssections with $D / t$ ratios 60 and 80 , respectively, are found to be lesser than normal CFST cross-sections. So it can be concluded that an increase in $D / t$ ratio does not improve significantly the bond strength of composite cross-sections. 


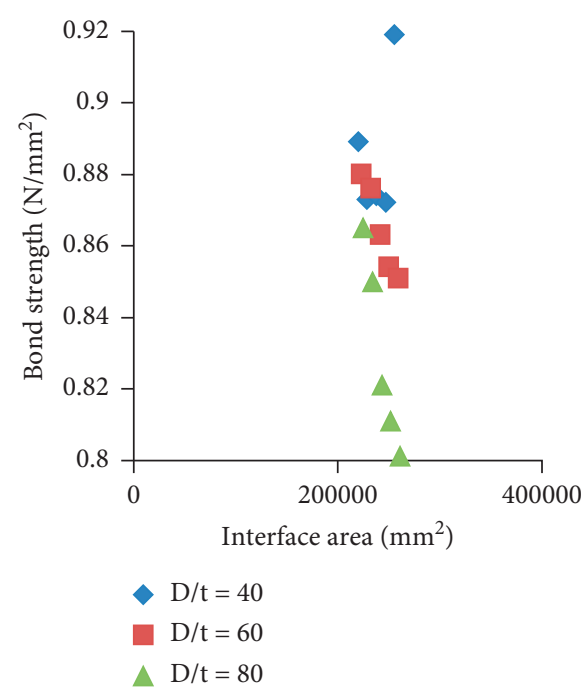

(a)

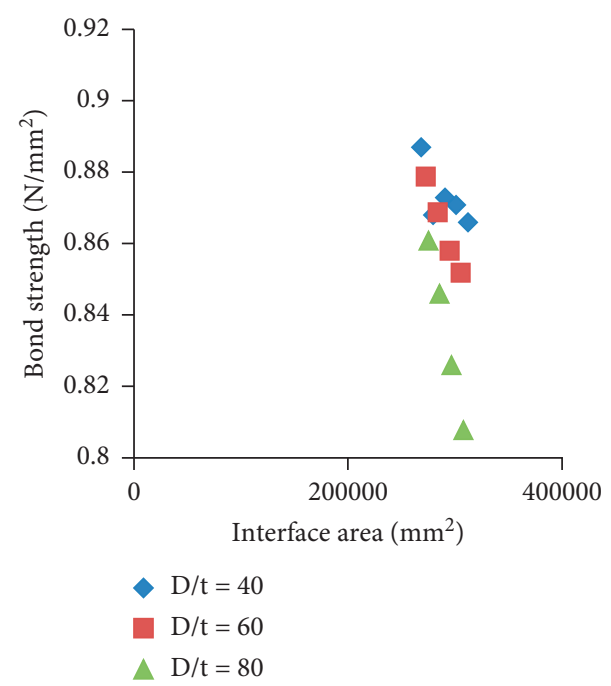

(b)

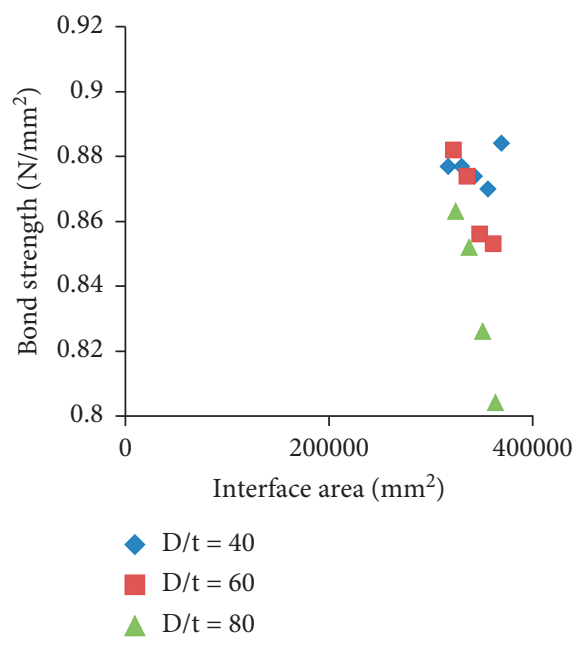

(c)

FIGURE 13: Variation in bond strength with Interface area. (a) Interface length $450 \mathrm{~mm}$. (b) Interface length $550 \mathrm{~mm}$. (c) Interface length $650 \mathrm{~mm}$.

TABLE 4: Comparison of bond strength of experimental specimens with proposed formula.

\begin{tabular}{lcccccc}
\hline Sl no. & Nomenclature & $\boldsymbol{\tau}_{\mathbf{u}(\mathbf{E X P})}(\mathrm{MPa})$ & $\boldsymbol{\tau}_{\mathbf{u}(\text { FEA })}(\mathrm{MPa})$ & $\tau_{\mathbf{u} \text { (proposed })}(\mathrm{MPa})$ & $\tau_{\mathbf{u}(\text { EXP })} / \tau_{\mathbf{u}(\text { FEA })}$ & $\tau_{\mathbf{u}(\text { EXP })} / \tau_{\mathbf{u}(\text { proposed })}$ \\
\hline 1 & SCCFC-4-O & 1.38 & 1.38 & 1.52 & 1.00 & 0.91 \\
2 & SCCFC-4-I & 0.72 & 0.74 & 0.81 & 0.97 & 0.89 \\
3 & SCCFC-3-O & 1.35 & 1.27 & 1.40 & 0.96 & 0.99 \\
4 & SCCFC-3-I & 0.85 & 0.86 & 0.95 & 0.99 & 0.89 \\
5 & CFST & 1.27 & 1.30 & 1.43 & 0.98 & \\
\hline
\end{tabular}

TABLE 5: Comparison of bond strength of numerical models with proposed formula.

\begin{tabular}{lccccc}
\hline Sl no. & Nomenclature & $\tau_{\mathbf{u}(\text { FEA })}(\mathrm{MPa})$ & $\tau_{\mathbf{u}(\text { proposed })}(\mathrm{MPa})$ & $\tau_{\mathbf{u}(\text { FEA })} / \tau_{\mathbf{u}(\text { CFST })}$ & $\tau_{\mathbf{u}(\text { propose d })} / \tau_{\mathbf{u}(\text { CFST })}$ \\
\hline 1 & SCCFC-40-2a & 0.884 & 0.972 & 1.017 & 1.119 \\
2 & SCCFC-40-3a & 0.882 & 0.970 & 1.015 & 1.116 \\
3 & SCCFC-40-4a & 0.885 & 0.974 & 1.018 & 1.121 \\
4 & SCCFC-40-5a & 0.879 & 0.967 & 1.004 & 1.113 \\
5 & SCCFC-40-6a & 0.873 & 0.960 & 1.105 \\
\hline
\end{tabular}


TABle 5: Continued.

\begin{tabular}{|c|c|c|c|c|c|}
\hline Sl no. & Nomenclature & $\tau_{\mathbf{u}(\text { FEA) }}(\mathrm{MPa})$ & $\tau_{\mathbf{u}(\text { proposed })}(\mathrm{MPa})$ & $\tau_{\mathbf{u}(F E A)} / \tau_{\mathbf{u}(C F S T)}$ & $\tau_{\mathbf{u}(\text { propose d) }} / \tau_{\mathbf{u}(\text { CFST) }}$ \\
\hline 6 & SCCFC-40-2b & 0.889 & 0.978 & 1.023 & 1.125 \\
\hline 7 & SCCFC-40-3b & 0.873 & 0.960 & 1.005 & 1.105 \\
\hline 8 & SCCFC- $40-4 b$ & 0.874 & 0.961 & 1.006 & 1.106 \\
\hline 9 & SCCFC-40-5b & 0.872 & 0.959 & 1.003 & 1.104 \\
\hline 10 & SCCFC-40-6b & 0.919 & 1.01 & 1.058 & 1.058 \\
\hline 11 & SCCFC-40-2c & 0.808 & 0.889 & 0.930 & 1.023 \\
\hline 12 & SCCFC- $40-3 c$ & 0.843 & 0.927 & 0.970 & 1.067 \\
\hline 13 & SCCFC-40-4c & 0.863 & 0.949 & 0.993 & 1.092 \\
\hline 14 & SCCFC- $40-5 c$ & 0.896 & 0.986 & 1.031 & 1.135 \\
\hline 15 & SCCFC-40-6c & 0.924 & 1.016 & 1.063 & 1.268 \\
\hline 16 & SCCFC-60-2a & 0.876 & 0.964 & 0.974 & 1.072 \\
\hline 17 & SCCFC-60-3a & 0.848 & 0.933 & 0.943 & 1.038 \\
\hline 18 & SCCFC-60-4a & 0.849 & 0.934 & 0.944 & 1.039 \\
\hline 19 & SCCFC-60-5a & 0.842 & 0.926 & 0.937 & 1.030 \\
\hline 20 & SCCFC-60-6a & 0.841 & 0.925 & 0.935 & 1.029 \\
\hline 21 & SCCFC-60-2b & 0.880 & 0.968 & 0.979 & 1.077 \\
\hline 22 & SCCFC-60-3b & 0.876 & 0.964 & 0.974 & 1.072 \\
\hline 23 & SCCFC-60-4b & 0.863 & 0.949 & 0.960 & 1.056 \\
\hline 24 & SCCFC-60-5b & 0.854 & 0.939 & 0.950 & 1.044 \\
\hline 25 & SCCFC-60-6b & 0.851 & 0.936 & 0.947 & 1.041 \\
\hline 26 & SCCFC-60-2c & 0.884 & 0.972 & 0.983 & 1.081 \\
\hline 27 & SCCFC-60-3c & 0.866 & 0.953 & 0.963 & 1.060 \\
\hline 28 & SCCFC-60-4c & 0.865 & 0.952 & 0.962 & 1.059 \\
\hline 29 & SCCFC-60-5c & 0.861 & 0.947 & 0.958 & 1.053 \\
\hline 30 & SCCFC-60-6c & 0.849 & 0.934 & 0.944 & 1.039 \\
\hline 31 & SCCFC-80-2a & 0.835 & 0.919 & 0.930 & 1.023 \\
\hline 32 & SCCFC-80-3a & 0.807 & 0.888 & 0.899 & 0.989 \\
\hline 33 & SCCFC-80-4a & 0.794 & 0.873 & 0.884 & 0.972 \\
\hline 34 & SCCFC-80-5a & 0.796 & 0.876 & 0.886 & 0.975 \\
\hline 35 & SCCFC-80-6a & 0.814 & 0.896 & 0.916 & 0.998 \\
\hline 36 & SCCFC-80-2b & 0.865 & 0.952 & 0.963 & 1.060 \\
\hline 37 & SCCFC-80-3b & 0.850 & 0.935 & 0.947 & 1.006 \\
\hline 38 & SCCFC-80-4b & 0.821 & 0.903 & 0.914 & 1.006 \\
\hline 39 & SCCFC-80-5b & 0.811 & 0.892 & 0.903 & 0.993 \\
\hline 40 & SCCFC-80-6b & 0.801 & 0.881 & 0.892 & 0.981 \\
\hline 41 & SCCFC-80-2c & 0.869 & 0.956 & 0.968 & 1.065 \\
\hline 42 & SCCFC-80-3c & 0.859 & 0.945 & 0.957 & 1.052 \\
\hline 43 & SCCFC-80-4c & 0.839 & 0.923 & 0.934 & 1.028 \\
\hline 44 & SCCFC-80-5c & 0.828 & 0.911 & 0.922 & 1.014 \\
\hline 45 & SCCFC-80-6c & 0.807 & 0.888 & 0.899 & 0.989 \\
\hline
\end{tabular}

\section{Conclusions}

(i) Outward rectangular-fluted cross-sections exhibit increased bond strength compared to inward fluted cross-sections due to high-stress concentration near the sharp edges in the inward fluted cross-sections.

(ii) Provision of inward flutes has a negative effect since local failure occurs near the sharp edges in the inward fluted cross-sections due to stress concentration.

(iii) Finite element software ABAQUS is capable of simulating the actual behavior within a margin of $4 \%$.

(iv) To simulate the interaction between steel and concrete, the surface-to-surface contact option in ABAQUS can be used.

(v) The proposed equation based on the angle of friction can predict the bond strength of CFST as well as fluted concrete-filled sections within a reasonable accuracy of $9 \%$.

(vi) For cross-sections with a higher $D / t$ ratio, an increase in the number of flutes does not enhance the bond strength.

(vii) For cross-sections with a lower $D / t$ ratio, an increase in the number of flutes increases the bond failure load by $15-29 \%$.

(viii) Bond strength is found to decrease with an increase in the interface area irrespective of the $D / t$ ratio.

(ix) Provision of rectangular flutes results in a higher bond failure load and significantly improves the composite action of CFST cross-sections.

\section{Abbreviations}

D: Diameter of specimen $(\mathrm{mm})$

$t_{\mathrm{s}}$ : Thickness of steel tube $(\mathrm{mm})$ 
$f_{\text {ck }}$ : Cube compressive strength $\left(\mathrm{N} / \mathrm{mm}^{2}\right)$

$\sigma_{u}$ : Ultimate stress $\left(\mathrm{N} / \mathrm{mm}^{2}\right)$

$\tau_{\mathrm{u}}$ : Bond strength $\left(\mathrm{N} / \mathrm{mm}^{2}\right)$

$E$ : Modulus of elasticity $\left(\mathrm{N} / \mathrm{mm}^{2}\right)$

$\sigma_{y}$ : Yield stress $\left(\mathrm{N} / \mathrm{mm}^{2}\right)$

$L$ : Length of specimen $(\mathrm{mm})$.

\section{Data Availability}

The data used to support the findings of this study are available from the corresponding author upon request.

\section{Conflicts of Interest}

The authors declare that there are no conflicts of interest regarding the publication of this paper.

\section{References}

[1] J. Moon, E. D. lehman, W. C. Roeder, and H.-E. Lee, "Strength of circular concrete-filled tubes with and without internal reinforcement under combined loading," Journal Structural Engineering, vol. 139, no. 12, pp. 1-12, 2013.

[2] B. R. Niranjan and H. Eramma, "Comparison of experimental values with EC 4, ACI-318, AISC-LRFD of concrete filled steel fluted columns for concentric load," American Journal of Engineering Research, vol. 3, no. 5, pp. 335-344, 2014.

[3] T. Zhong, Z.-B. Wang, and Q. Yu, "Finite Element Modelling of Concrete-filled steel stub columns under axial compression," Journal Constructional Steel Research, vol. 89, no. 10, pp. 121-131, 2013.

[4] X. Qu, Z. Chen, D. A. Nethercot, L. Gardner, and M. Theofanous, "Push-out tests and bond strength of rectangular CFST columns," Steel and Composite Structures, vol. 19, no. 1, pp. 21-41, 2015.

[5] R. Abendeh, H. S. Ahmad, and Y. M. Hunaiti, "Experimental studies on the behavior of concrete-filled steel tubes incorporating crumb rubber," Journal of Constructional Steel Research, vol. 122, pp. 251-260, 2016.

[6] Y. Ouyang and A. K. H. Kwan, "Finite element analysis of square concrete-filled steel tube (CFST) columns under axial compressive load," Engineering Structures, vol. 156, pp. 443459, 2018.

[7] ASTM Standards A370-18, Test Methods and Definitions for Mechanical Testing of Steel Products, ASTM Standards, West Conshohocken, PA, USA, 2018.

[8] H. Liu, Y. Wang, M. He, Y. Shi, and H. Waisman, "Strength and ductility performance of concrete-filled steel tubular columns after long-term service loading," Engineering Structures, vol. 100, pp. 308-325, 2015.

[9] Z. Lai, A. H. Varma, and L. G. Griffis, "Analysis and design of non-compact and slender CFT beam-columns," Journal of Structural Engineering, vol. 142, no. 1, pp. 1-14, 2015.

[10] J. Thomas and T. N. Sandeep, "Capacity of short circular CFST columns with inner vertical plates welded intermittently," Journal Constructional Steel Research, vol. 165, pp. 1-12, 2020. 